\title{
KAJI KAPASITAS PENDINGINAN IKAN DENGAN MENGGUNAKAN ES DALAM KEMASAN PLASTIK
}

\author{
Rikhard Ufie $^{1)}$, Roy R. Lekatompessy ${ }^{2)}$, Zico Marlissa ${ }^{3)}$ \\ e-mail: ${ }^{1)}$ rikhardufie@ fatek.unpatti.co.id \\ ${ }^{1,3)}$ Program Studi Teknik Mesin Fakultas Teknik Universitas Pattimura \\ ${ }^{2)}$ Program Studi Teknik Mesin Politeknik Negeri Ambon
}

\begin{abstract}
ABSTRAK
Kaji eksperimental ini dilakukan untuk mengetahui pengaruh perbandingan massa es dan ikan terhadap karakteristik perubahan suhu penyimpanan ikan dalam coolbox.; kapasitas pendinginan ikan; besar massa es yang tersisa pada akhir proses penyimpanan. Sesuai hasil penelitian yang dilakukan diperoleh bahwa semakin meningkatnya massa es yaitu untuk perbandingan massa ikan dan es sebesar 3:1, 2:1, 1:1, maka akan semakin meningkat laju pendinginan yakni sebesar, 0,061; 0,062 dan $0,123{ }^{\circ} \mathrm{C} /$ menit, semakin rendah suhu pendinginan ikan yang dapat dicapai, yaitu untuk perbandingan $3: 1,2: 1,1: 1$ diperoleh sebesar, $6{ }^{\circ} \mathrm{C}, 4,5^{\circ} \mathrm{C}$ dan $0,4^{\circ} \mathrm{C}$, dan semakin rendah pula suhu akhir penyimpanan yang dapat dipertahankan yakni sebesar, $19^{\circ} \mathrm{C}, 14^{\circ} \mathrm{C}$, dan $7^{\circ} \mathrm{C}$. Diketahui pula bahwa terdapat perbedaan kapasitas pendinginan dengan semakin meningkatnya massa es, pada perbandingan massa ikan dan masing-masing sebesar 3:1, 2:1, dan 1:1 yakni sebesar $500.320 \mathrm{~J} ; 590.300 \mathrm{~J}$ dan $517.851 \mathrm{~J}$ pada proses pendinginan dari suhu awal hingga suhu terendah dan sebesar 500,320 J; 590,300 J; dan517,851 J, sedangkan massa es yang tersisa pada akhir proses penyimpanan untuk perbandingan massa ikan sebesar 3:1, 2:1, dan 1:1 adalah sebesar 0,04543 kg, 0,0505 kg, dan $0,8336 \mathrm{~kg}$
\end{abstract}

Kata kunci: pendinginan ikan, coolbox, es dalam kemasan plastik,

\section{PENDAHULUAN}

Ikan termasuk produk yang akan membusuk jika dibiarkan terus pada suhu lingkungan tanpa proses pendinginan. Pada penanganan ikan segar (fresh fish) ikan hasil tangkapan didinginkan di atas suhu beku, sedangkan pada penanagan ikan beku (frozen fish) ikan didinginkan hingga berada di bawah suhu beku.

Cara pendinginan sederhana yang umumnya ditempuh pada proses penangnan ikan segar yakni menggunakan bongkahan es. Selain sederhana, dengan cara ini suhu ikan dapat diturunkan tetapi tetap berada di atas suhu beku. Ikan yang diawetkan dengan demikian tidak akan mengalami proses pembekuan.

Pendinginan ikan segar selama proses pengiriman ikan dengan pesawat udara, juga dilakukan dengan penggunaan es. Ikan disimpan di dalam coolbox dan didinginkan dengan es dalam kemasan plastik dengan maksud agar air yang berasal dari pencairan es tetap tertampung dalam plastik sehingga tidak membasahi tubuh ikan maupun menggenangi coolbox.

Oleh karena coolbox yang digunakan berukuran tertentu, maka proses pendinginan akan tergantung pada perbandingan massa ikan dan es yang digunakan.

Melalui penelitian ini hendak diketahui: (1) pengaruh perbandingan massa es dan ikan terhadap karakteristik perubahan suhu penyimpanan ikan dalam coolbox.; (2) pengaruh perbandingan massa es dan ikan terhadap kapasitas pendinginan ikan; (3) besar massa es yang tersisa pada akhir proses penyimpanan.

\section{KAJIAN TEORI DAN METODOLOGI 1. Perhitungan Beban pendinginan ikan}

Kalor sensibel yang harus dipindahkan untuk mendinginkan ikan dari suhu awal ke suhu penyimpanan, dapat dihitung dengan persamaan:

dimana:

$$
Q_{f}=m_{f} c_{p}\left(T_{f 1}-T_{f 2}\right)
$$

$Q_{f}=$ kalor sensibel ikan yang harus dipindahkan, kJ

$m_{f}=$ massa ikan, $\mathrm{kg}$

$c_{p}=$ kalor spesifik ikan di atas pembekuan, $\mathrm{kJ} /(\mathrm{kg} . \mathrm{K})$

$T_{f l}=$ suhu awal ikan, ${ }^{\circ} \mathrm{C}$

$T_{f 2}=$ suhu penyimpanan ikan, $0^{\circ} \mathrm{C}$

Beban pendinginan ikan yang dinyatakan dalam laju perpindahan panas selanjutnya dapat dihitung dengan persamaan:

$$
q_{f}=\frac{Q_{f}}{3600 \times n_{f}}
$$

dimana:

$q_{f}=$ beban pendinginan ikan, $\mathrm{kW}$

$n_{f}=$ selang waktu pendinginan ikan, jam. 


\section{Perhitungan Beban Transmisi}

Beban transmisi kalor yang dinyatakan dalam laju aliran kalor melalui dinding coolbox, dapat dihitung dengan persamaan:

$$
q_{\text {trans }}=U A \Delta T
$$

dimana:

$q_{\text {trans }}=$ laju transmisi kalor melalui dinding coolbox $\mathrm{kW}$

$A=$ luas bidang perpindahan panas, $\mathrm{m}^{2}$

$\Delta T=$ beda antara suhu udara luar dan suhu di Dalam coolbox, ${ }^{\circ} \mathrm{C}$

$U=$ koefisien perpindahan kalor menyeluruh dari dinding komposit yang dihitung dengan persamaan :

$$
U=\frac{1}{1 / f_{0}+\sum_{i=1}^{n} x_{i} / k_{i}+1 / h_{i}}
$$

di mana:

$f_{o}=$ konduktivitas film dinding luar, $\mathrm{W} /\left(\mathrm{m}^{2} \cdot \mathrm{K}\right)$

$x_{i}=$ tebal lapisan ke $\mathrm{i}, \mathrm{m}$

$k_{i}=$ konduktivitas lapisan $\mathrm{ke} \mathrm{i}, . \mathrm{W} /(\mathrm{m} \cdot \mathrm{K})$

$h_{i}=$ koefisien perpindahan panas konveksi dinding dalam, $\mathrm{W} /\left(\mathrm{m}^{2} \cdot \mathrm{K}\right)$

\section{Perhitungan Kapasitas Pendinginan}

Kapasitas pendinginan pada cold box tergantung pada jumlah kalor yang dibutuhkan untuk pemanasan dan peleburan es dari suhu awalnya hingga suhu air yang terbentuk, yang dapat dihitung dari persamaan:

$$
Q_{i c e}=m_{i c e}\left[c_{i 1}\left(T_{i 1}-T_{f}\right)+h_{s f}+c_{i 2}\left(T_{f}-T_{w 2}\right)\right]
$$

dimana:

$Q_{w}=$ kalor sensibel air laut yang dipindahkan, $\mathrm{kJ}$

$m_{w}=$ massa air laut, $\mathrm{kg}$

$c_{i 1}=$ kalor spesifik es di bawah pembekuan, $\mathrm{kJ} /(\mathrm{kg} . \mathrm{K})$

$c_{i 2}=$ kalor spesifik es di atas pembekuan, $\mathrm{kJ} /(\mathrm{kg}$. $\mathrm{K})$

$T_{i l}=$ suhu awal es, ${ }^{\circ} \mathrm{C}$

$T_{f}=$ suhu peleburan es, ${ }^{\circ} \mathrm{C}$

$T_{i f}=$ suhu akhir air yang terbentuk, ${ }^{\circ} \mathrm{C}$

Kapasitas pendinginan oleh es yang dinyatakan dalam laju perpindahan kalor selanjutnya dapat dihitung dengan persamaan:

$$
q_{\text {ice }}=\frac{Q_{\text {ice }}}{3600 \times t}
$$

dimana:

$q_{\text {ice }}=$ laju perpindahan kalor pada es, $\mathrm{kW}$

$t=$ waktu peleburan/pencairan es, jam.

\section{Fenomena Peleburan Es (ice melting)}

Fenomena peleburan es dapat didekati menurut skema pendekatan massa atur (control massa) sesuai Gambar 1.

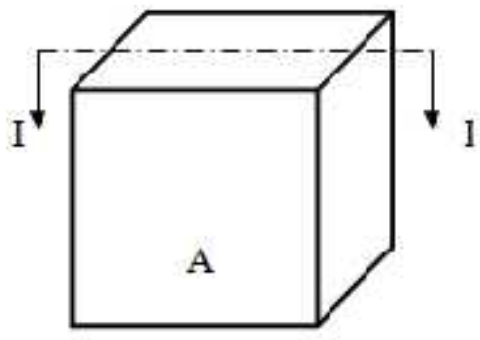

(a) Kubus es

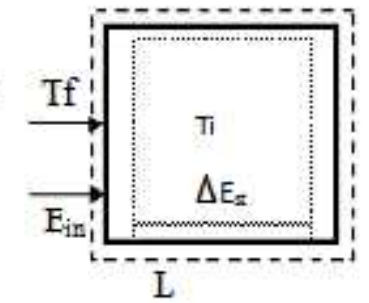

(b) Penampang I-I
Gambar 1. Skema Massa Atur proses Peleburan Es

Sesuai Hukum I Termodinamika, jumlah energi masuk $=$ jumlah energi yang tersimpan, sehingga dapat diperoleh persaamaan:

$$
\begin{aligned}
& E_{\text {in }}=\Delta E_{s t} \\
& q_{\text {in }} \cdot d t=\left\lfloor c p\left(T_{i}-T_{f}\right)+h_{s f}\right\rfloor \cdot d m_{\text {ice }}
\end{aligned}
$$

atau

$$
q_{\text {in }}=\frac{d m_{i c e}}{d t_{m}}\left[c p\left(T_{i}-T_{f}\right)+h_{s f}\right] .
$$

dimana

$$
\begin{aligned}
& q_{\text {in }}= \text { laju perpindahan kalor memasuki volume } \\
& \text { atur, } \mathrm{W}
\end{aligned}
$$

Ruas kanan Persamaan (9) menunjukaan besar laju perpindahan kalor dari lingkungan yang hendak didinginkan sedangkan ruas kiri Persamaan (9) menunjukkan laju peleburan es.

\section{Metodologi}

Penelitian ini dilakukan dengan menggunakan coolbox berupa kotak steoreofoam berukuran $(51 \mathrm{x}$ $42 \times 31) \mathrm{cm}^{3}$ dengan tebal dinding $3 \mathrm{~cm}$ sebanyak 3 buah. Pengukuran suhu dilakukan dengan menggunakan termometer digital yang dihubungan dengan termokopel tipe $\mathrm{K}$ dan switchchannel, sedangkan bahan yang digunakan yaitu ikan jenis cakalang (Katsuwonus pelamis) sebanyak 12 ekor dan es batangan dalam kemasan plastik yang ditimbang dengan perbandingan massa ikan dan masaa es sebagamana ditunjukkan pada Tabel 1. 
Tabel 1. Perbandingan Massa Ikan dan Es

\begin{tabular}{|c|c|c|}
\hline Perbandingan & ikan $(\mathrm{kg})$ & es $(\mathrm{kg})$ \\
\hline$(1: 1)$ & 3,8030 & 3,8028 \\
\hline$(2: 1)$ & 4,6010 & 2,3000 \\
\hline$(3: 1)$ & 4,4210 & 1,4690 \\
\hline Jumlah & 12,8250 & 7,5718 \\
\hline
\end{tabular}

Ikan yang telah dicuci ditimbang dan dimasukkan masing-masing ke dalam coolbox yang tersedia. Es batangan dalam kemasan plastik ditimbang dan dimasukan kedalam coolbox yang tersedia, Termokopel dipasang pada tubuh ikan, ruang dalam dan lingkungan coolbox dan dihubungkan dengan termometer digital melalui switchchannel. Coolbox yang telah terisi ikan dan es ditutup kedap dengan menggunakan "selotipe". Suhu tubuh ikan, ruang dalam dan lingkungan coolbox dicatat setiap selang waktu 10 menit.

\section{HASIL DAN PEMBAHASAN}

\section{Karakteristik Perubahan Suhu Penyimpanan}

Karakteristik perubahan suhu penyimpanan ikan dalam coolbox ditunjukkan pada Gambar 3. Pengukuran dilakukan untuk ketiga coolbox dengan perbandingan masa es dan massa ikan masingmasing sebesar $1: 1 ; 2: 1$ dan 3:1 selama 930 menit (15,5 jam).

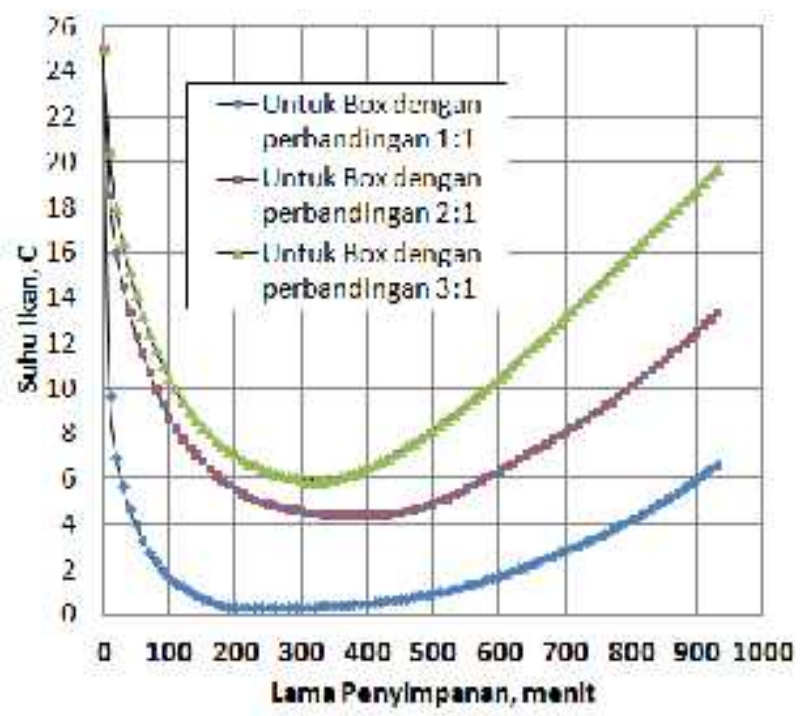

Gambar 2. Grafik karakteristik perubahan suhu penyimpnan ikan

Terlihat bahwa pada proses pendinginan dengan perbandingan massa ikan dan es 1:1 terjadi penurunan suhu ikan yang lebih cepat dan juga dapat dicapai suhu akhir pendinginan yang lebih rendah dibanding proses pendinginan dengan perbandingan massa ikan dan es sebesar 2:1 maupun 3:1. Suhu penyimpanan terendah ini pun terlihat dapat dipertahankan lebih lama sebelum suhu ikan kembali bergerak naik. Para proses pendinginan dengan perbandingan ikan dan es sebesar 1:1 ini, suhu akhir penyimpanan juga terlihat lebih rendah.

Besar laju penurunan suhu, temperatur terendah, laju peningkatan kembali suhu ikan, dan suhu akhir penyimpanan untuk ketiga perbandingan ditunjukan pada Tabel 2. dan juga Gambar 2.

Tabel 2. Besar dan Laju Penurunan Suhu Ikan selama Penyimpanan

\begin{tabular}{|c|c|c|c|c|}
\hline \multirow[t]{2}{*}{ Busurun } & \multicolumn{3}{|c|}{$\begin{array}{l}\text { Perbandingan } \\
\text { masa ilsan dan massa os }\end{array}$} & \multirow[t]{2}{*}{ Stlutu } \\
\hline & $1: 1$ & $2: 1$ & $3: 1$ & \\
\hline $\begin{array}{l}\text { Suku awal } \\
\text { isan }\end{array}$ & 25 & 25 & 25 & $c$ \\
\hline 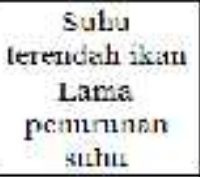 & 190 & 3.30 & 310 & menit \\
\hline $\begin{array}{c}\text { Laju } \\
\text { pominnmon } \\
\text { suhu zats-rata }\end{array}$ & 0,129 & 0,062 & $D_{2} 061$ & Comenit \\
\hline $\begin{array}{c}\text { Subu akhir } \\
\text { Panyimpanan }\end{array}$ & 0,7 & 13,4 & 19,3 & $c$ \\
\hline $\begin{array}{c}\text { Liunat } \\
\text { kenaikan } \\
\text { suht }\end{array}$ & 740 & 600 & 620 & menit \\
\hline $\begin{array}{c}\text { Laju } \\
\text { kenaikan } \\
\text { sulhu rata-rata }\end{array}$ & 0.0085 & 0,0148 & 6.022 .3 & Cmenit \\
\hline
\end{tabular}

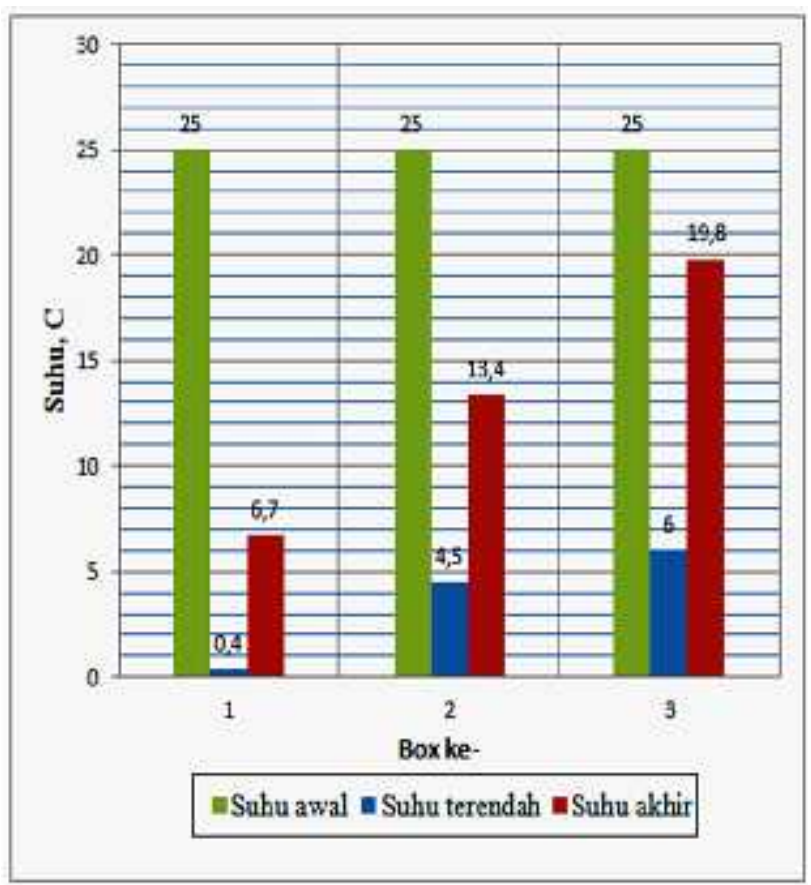

Gambar 2. Suhu awal, suhu terendah dan suhu akhir penyimpanan pada tiap coolbox.

Laju pendinginan, suhu penyimpanan terendah maupun suhu akhir penyimpanan dengan demikian sangat tergantung pada massa es yang tersedia. Semakin besar massa es yang digunakan dibanding massa ikan yang hendak didinginkan, semakin besar 
laju pendinginan ikan, semakin rendah suhu penyimpanan yang dapat dicapai, semakin lama suhu terndah dapat dipertahankan, semakin lambat kenaikan kembali suhu ikan dan semakin rendah suhu akhir penyimpanan ikan.

\section{Kapasitas Pendinginan}

Hasil perhitungan kapasitas pendinginan pada proses pendinginan ikan dari suhu awal hingga suhu terendah ditunjukkan pada Tabel 3, sedangkan pada proses kenaikan kembali suhu ikan dari suhu terendah hingga suhu akhir penyimpanan ditunjukkan pada Tabel 4.

Tabel 3. Hasil Perhitungan Kapasitas Pendinginan pada proses pendinginan ikan dari suhur awal hingga suhu terendah

\begin{tabular}{|c|c|c|c|c|c|}
\hline \multirow[t]{2}{*}{ No. } & \multirow[t]{2}{*}{ Besaran } & \multicolumn{3}{|c|}{$\begin{array}{c}\text { Perbandingan massa ikan: } \\
\text { massa es }\end{array}$} & \multirow[t]{2}{*}{ Satuan } \\
\hline & & $1: 1$ & $2: 1$ & $3: 1$ & \\
\hline 1 & Massa ikan, mf & 3,8030 & 4,6010 & 4,4210 & $\mathrm{~kg}$ \\
\hline 2 & Kalor spesifik ikan & 3.180 & 3.180 & 3.180 & $J(\mathrm{~kg} C)$ \\
\hline 3 & Suhu awal ikan & 25 & 25 & 25 & C \\
\hline 4 & Suhu terendah Kan & 0,4 & 4,5 & 6 & C \\
\hline 5 & Kalor total ikan, Qf & 29750 & 2999 & 267.1 & $\mathrm{~J}$ \\
\hline 6 & Suhu lingkungan & 27,7 & 27,0 & 27.0 & c \\
\hline 7 & Suhu coolbox & 13,02 & 14,94 & 15,92 & c \\
\hline 8 & $\begin{array}{l}\text { Koefisien perpindahan } \\
\text { panas total, } U\end{array}$ & 1,156 & 1,156 & 1,156 & $\mathrm{~W} / \mathrm{m} 2 \mathrm{c}$ \\
\hline 9 & $\begin{array}{c}\text { Luas permukaan } \\
\text { perpindahan panas, } \mathrm{A}\end{array}$ & 1,0515 & 1,0515 & 1,0515 & $\mathrm{~m} 2$ \\
\hline 10 & Lajukalor transmisi, qquo & 17,791 & 14,665 & 13,480 & $\mathrm{~W}(=\mathrm{J} / \mathrm{s})$ \\
\hline 11 & Lama penđinginan, $\Delta t$ & 190 & 330 & 310 & menit \\
\hline 12 & $\begin{array}{c}\text { Kalor transmisi total, } \\
\text { Qtrans }\end{array}$ & 202.82 & 290.36 & 250.73 & $J$ \\
\hline 13 & Kalor spesifik air, cpair & 4.190 & 4.190 & 4.190 & $I(\mathrm{kgC})$ \\
\hline 14 & $\begin{array}{c}\text { Kalor laten peleburan es, } \\
\text { hsf }\end{array}$ & 335.00 & 335.00 & 335.00 & $J / \mathrm{kg}$ \\
\hline 15 & Kalor spesifik es, cpea & 2.100 & 2.100 & 2.100 & $J /(\mathrm{kg} C)$ \\
\hline 16 & $\begin{array}{l}\text { Suhu es di bawah titik } \\
\text { belou }\end{array}$ & -6 & -6 & -6 & c \\
\hline 17 & Suhu lebur es \& 1 atm & 0 & 0 & 0 & c \\
\hline 18 & $\begin{array}{c}\text { Suhu terendah } \\
\text { penyimpanan ikan, }\end{array}$ & 0,4 & 4,5 & 6 & C \\
\hline 19 & $\begin{array}{l}\text { Massa es yang melebur } \\
\text { (cairan) }\end{array}$ & 1.4324 & 1,6108 & 1,3893 & $\mathrm{~kg}$ \\
\hline 20 & Massa es total & 3,8280 & 2,3000 & 1,4690 & $\mathrm{~kg}$ \\
\hline 21 & $\begin{array}{c}\text { Massa es sisa yang } \\
\text { behum melebur (padatan) }\end{array}$ & 2,3956 & 0,6892 & 0,0797 & $\mathrm{~kg}$ \\
\hline 22 & \begin{tabular}{|c|}
$\begin{array}{c}\text { Kapasitas pendinginan } \\
\text { oleh massa es yang } \\
\text { mencair }\end{array}$ \\
\end{tabular} & 500.320 & 590,300 & 517.851 & $\mathbf{J}$ \\
\hline
\end{tabular}

Terlihat bahwa pada proses pendinginan dengan perbandingan massa ikan dan es sebesar 1:1, kapasitas pendinginan oleh massa es yang melebur ini adalah $500.320 \mathrm{~J}$ yaitu untuk menurunankan suhu ikan dari suhu awal $25^{\circ} \mathrm{C}$ hingga suhu terendah $0,4^{\circ} \mathrm{C}$. Pada pada proses pendinginan dengan perbandingan massa ikan dan es sebesar 2:1, kapasitas pendinginan oleh massa es yang melebur pada pendinginan dengan perbandingan massa ikan dan massa es sebesar 2:1 ini adalah $590.300 \mathrm{~J}$ yaitu untuk dapat menurunankan suhu ikan dari suhu awal $25^{\circ} \mathrm{C}$ hingga suhu terendah $4,5^{\circ} \mathrm{C}$. Sedangkan pada proses pendinginan dengan perbandingan massa ikan dan es sebesar 3:1, kapasitas pendinginan oleh massa es yang melebur adalah $517.851 \mathrm{~J}$ yaitu untuk menurunankan suhu ikan dari suhu awal $25^{\circ} \mathrm{C}$ hingga suhu terendah $6^{\circ} \mathrm{C}$.

Tabel 4. Hasil Perhitungan Kapasitas Pendinginan pada proses kenaikan kembali suhu ikan dari suhu terendah hingga suhu akhir penyimpanan

\begin{tabular}{|c|c|c|c|c|c|}
\hline \multirow{2}{*}{ No } & \multirow{2}{*}{ Bearas } & \multicolumn{3}{|c|}{$\begin{array}{c}\text { Perbandingas mass ikas: masse } \\
\text { a }\end{array}$} & \multirow{2}{*}{ Satas: } \\
\hline & & $1: 1$ & $2: 1$ & 3.1 & \\
\hline 1 & Saba lispkangan & 26,11 & 26,11 & 26,11 & c \\
\hline 2 & Sulu ber nate? & 13,18 & 16,15 & 19,82 & c \\
\hline 3 & $\begin{array}{l}\text { Koefisien perpiadahan } \\
\text { pusas total, } \mathrm{C}\end{array}$ & 1,1566 & 1,1666 & 1,1566 & W/mec \\
\hline 4 & $\begin{array}{c}\text { Lus pernukana } \\
\text { perpiadahon pass, A }\end{array}$ & 1,0515 & 1,0515 & 1,0615 & $m 2$ \\
\hline 5 & $\begin{array}{c}\text { Laju kalor trassaisi, } \\
\text { qumas }\end{array}$ & 15,7247 & 12,1137 & 7,6519 & $W(=\mathrm{J} / \mathrm{s})$ \\
\hline 6 & Luma pendinfisan, It & 740 & 600 & 620 & menit \\
\hline 7 & Lrme pendisgisus, It & 4.400 & 36.000 & 37.200 & 3 (detik) \\
\hline 8 & $\begin{array}{c}\text { Kalor trasamivi pada } \\
\text { prose kessikas suba } \\
\text { ikas, Qtmas }\end{array}$ & $698.177,8$ & $436.093,3$ & $284.651,9$ & J \\
\hline 9 & Massu ikas, mf & 3,8030 & 4,6010 & 4,4210 & kst \\
\hline 10 & Kalor spesifik ikan, $\mathbf{~ p f}$ & 3.180 & 3.180 & 3.190 & $J /(\mathrm{kg} C)$ \\
\hline 11 & $\begin{array}{c}\text { Massa es yong telat } \\
\text { melebur }\end{array}$ & 1,4324 & 1,6108 & 1,3593 & $\mathrm{~kg}$ \\
\hline 12 & Kalor spesifik air, CpW & 4.190 & 4.190 & 4.190 & $3 /(\operatorname{kg} C)$ \\
\hline 13 & \begin{tabular}{c|} 
Sahu terescah \\
pesyiapasas ilas,
\end{tabular} & 0,4 & 4,5 & 6 & c \\
\hline 14 & \begin{tabular}{|c|}
$\begin{array}{c}\text { Suhu akbir peayimpana } \\
\text { ikan }\end{array}$ \\
\end{tabular} & 6,7 & 13,4 & 19,8 & $\mathrm{c}$ \\
\hline 15 & $\begin{array}{c}\text { Kalor keanikas kembali } \\
\text { subu ikan }\end{array}$ & $76.189,3$ & $130.217,5$ & $194.011,2$ & J \\
\hline 16 & $\begin{array}{c}\begin{array}{c}\text { Kalor keasikas suhs } \\
\text { massu es youg telab } \\
\text { melebur }\end{array} \\
\end{array}$ & $37,812,6$ & $60.059,796$ & $80.332,6$ & 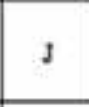 \\
\hline 17 & $\begin{array}{c}\text { Kalor total dori ikas das } \\
\text { masss es }\end{array}$ & $114.001,6$ & $196.287,3$ & $274.343,7$ & $s$ \\
\hline 18 & $\begin{array}{c}\begin{array}{c}\text { Sisa Kulor trasinisi } \\
\text { yasg bams ditasgani } \\
\text { massa e }\end{array} \\
\end{array}$ & $684.176,2$ & $245.806,1$ & $10,308,2$ & J \\
\hline 19 & $\begin{array}{c}\begin{array}{c}\text { Masu es yg melebur } \\
\text { ustak menasgani sisa } \\
\text { Kalor trasimai }\end{array} \\
\end{array}$ & 1,56198 & 0,63554 & 0,02543 & $\mathrm{~kg}$ \\
\hline 20 & $\begin{array}{c}\text { Sia masua e pas belam } \\
\text { melebar (podatas) pada } \\
\text { akhir penyimpanan }\end{array}$ & 0,8336 & 0,0505 & 0,0543 & $\mathrm{~kg}$ \\
\hline$n$ & $\begin{array}{c}\begin{array}{c}\text { Kapssitas peadinginsa } \\
\text { oleh manu a yang } \\
\text { melebur }\end{array} \\
\end{array}$ & 500.320 & 590.300 & 517.851 & J \\
\hline
\end{tabular}

Selanjutnya dari hasil perhitungan pada Tabel 4 selama proses kenaikan kembali suhu ikan dari suhu terendah hingga suhu akhir penyimpanan, massa es yang melebur pada coolbox dengan perbandingan massa ikan dan massa es sebesar 1:1 adalah sebesar $1,56198 \mathrm{~kg}$ dengan kapasitas pendiginan $500,320 \mathrm{~J}$; pada coolbox dengan perbandingan massa ikan dan massa es sebesar 2:1 adalah sebesar $0,63864 \mathrm{~kg}$ dengan kapasitas pendinginan 590,300 J; sedangkan pada coolbox dengan perbandingan massa ikan dan massa es sebesar 3:1 adalah sebesar $0,02543 \mathrm{~kg}$ dengan kapasitas pendinginan 517,851 J 


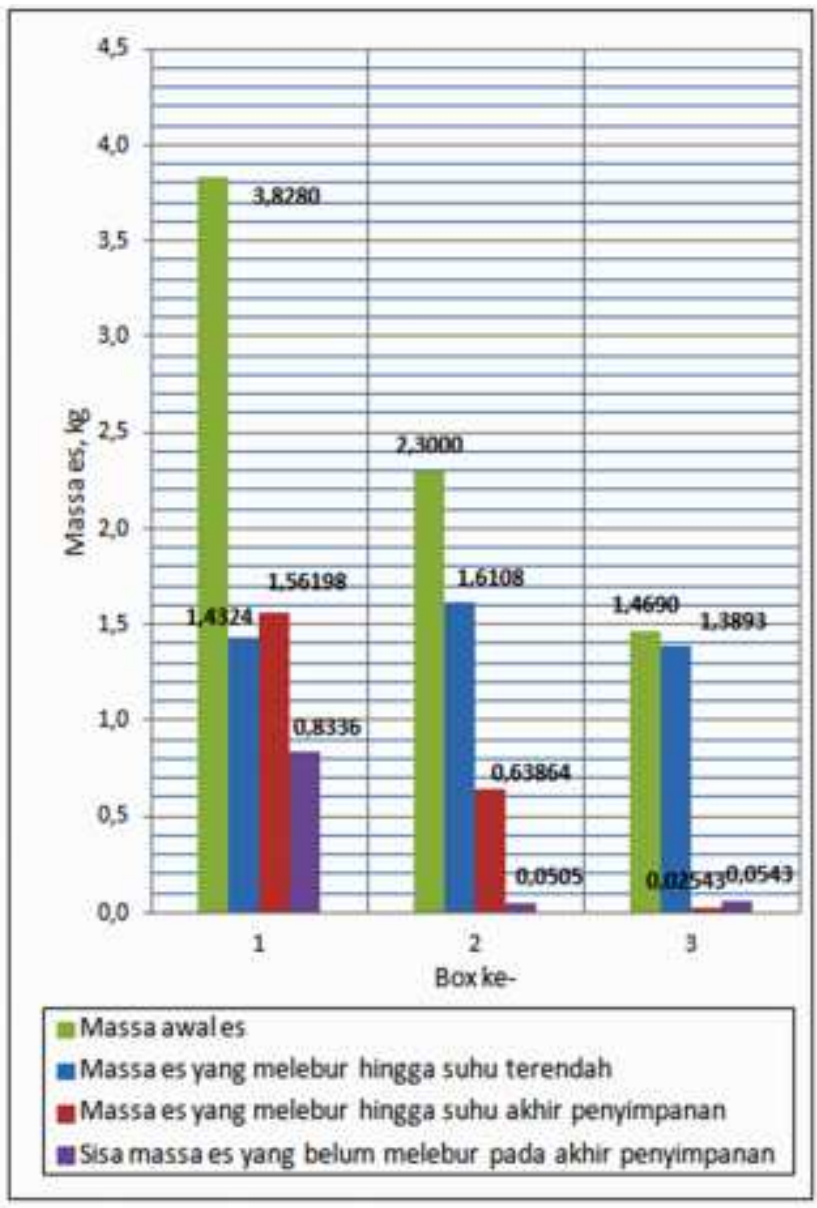

Gambar 3. Grafik Perubahan massa es dari awal hingga akhir proses pendinginan pada tiap coolbox.

Jumlah massa es pada setiap tahapan pendinginan mulai dari awal hingga akhir penyimpanan selanjutnya ditunjukkan pada Gambar 3. Terlihat pula bahwa masa es yang masih berbentuk padatan pada akhir proses pendinginan yakni setelah 930 menit atau 15,5 jam, masingmasing adalah sebesar $0,8336 \mathrm{~kg} ; 0,0505 \mathrm{~kg}$; dan $0,04543 \mathrm{~kg}$.

\section{KESIMPULAN}

Dari hasil pengujian dengan prototipe pendingin dan pengering terpadu yang digunakan dapatlah disimpulkan beberapa hal sebagai berikut:

(1) Semakin meningkatnya massa es yaitu untuk perbandingan massa ikan dan es sebesar 3:1, 2:1, 1:1, maka akan semakin meningkat laju pendinginan yakni sebesar, 0,$061 ; 0,062$ dan $0,123{ }^{\circ} \mathrm{C} /$ menit, semakin rendah suhu pendinginan ikan yang dapat dicapai, yaitu untuk perbandingan $3: 1,2: 1,1: 1$ diperoleh sebesar, $6{ }^{\circ} \mathrm{C}, 4,5^{\circ} \mathrm{C}$ dan $0,4^{\circ} \mathrm{C}$, dan semakin rendah pula suhu akhir penyimpanan yang dapat dipertahankan yakni sebesar, $19^{\circ} \mathrm{C}, 14^{\circ} \mathrm{C}$, dan $7^{\circ} \mathrm{C}$.

(2) Terdapat perbedaan kapasitas pendinginan dengan semakin meningkatnya massa es, pada perbandingan massa ikan dan masing-masing sebesar 3:1, 2:1, dan 1:1 yakni sebesar 500.320 $\mathrm{J} ; 590.300 \mathrm{~J}$ dan $517.851 \mathrm{~J}$ pada proses pendinginan dari suhu awal hingga suhu terendah dan sebesar $500,320 \mathrm{~J}$; 590,300 J; dan $517,851 \mathrm{~J}$.

(3) Massa es yang tersisa pada akhir proses penyimpanan untuk perbandingan massa ikan sebesar 3:1, 2:1, dan 1:1 adalah sebesar 0,04543 $\mathrm{kg}, 0,0505 \mathrm{~kg}$, dan $0,8336 \mathrm{~kg}$

\section{DAFTAR PUSTAKA}

ASHRAE, (1990): Fundamentals Handbook, American Society of Heating, Refrigerating and Air-Contioning Enggineer, Inc. Atlanta.

Arora, (2001): Refrigeration and Air Conditioning. McGraw-Hill International Edition, Boston/ Singapore.

Incropera F.P., and De Witt, D.P., (1990): Fundamentals of Heat and Mass Transfer. $3^{\text {rd }}$ ed. John Wiley\&Sons. New York..

Stoecker W.F, and J.W Jones, 1989, Refrigerasi dan Pengkondisian Udara. Edisi kedua, Alih bahasa Suratman Hara, Penerbit Erlangga, Jakarta 